\title{
A POLÍTICA ECONÔMICA BRASILEIRA PÓS-CRISE DE 2008 SOB A PERSPECTIVA DAS TEORIAS DE KEYNES E HAYEK
}

\author{
Thiago Sampaio Elias ${ }^{1}$ \\ Stéfani Clara da Silva Bezerra ${ }^{2}$
}

\section{RESUMO}

As teorias dos ciclos econômicos de John Maynard Keynes e Friedrich August von Hayek têm muita relevância até os dias atuais nos estudos econômicos. Com o advento da crise econômica mundial, o governo brasileiro utilizou o Estado para interferir na economia estimulando o crédito e aumentando os gastos públicos. Esta medida teve êxito de forma temporária. A mudança de governo alterou profundamente a política econômica do país com a política de austeridade fiscal. São estas políticas econômicas em diferentes momentos do país pós-crise de 2008 que serão abordadas no presente estudo, tendo como base as teorias de Keynes e Hayek.

Palavras-Chave: Keynes. Hayek. Crise econômica mundial. Economia brasileira. Finanças Públicas.

\section{BRAZILIAN ECONOMIC POLICY AFTER THE 2008 CRISIS UNDER THE PERSPECTIVE OF KEYNES AND HAYEK THEORIES}

\begin{abstract}
The business cycle theories of John Maynard Keynes and Friedrich August von Hayek are very relevant to the present day in economic studies. With the advent of the world economic crisis, the Brazilian government used the state to interfere with the economy by stimulating credit and increasing public spending. This measure was temporarily successful. The change of government profoundly altered the economic policy of the country with the policy of fiscal austerity. It is these economic policies at different times in the post-crisis country of 2008 that will be addressed in the present study, based on Keynes and Hayek's theories.
\end{abstract}

Keywords: Keynes. Hayek. World economic crisis. Brazilian economy. Public finance.

\section{INTRODUÇÃO}

\footnotetext{
${ }^{1}$ Mestrando em Direito Constitucional Público e Teoria Política pela Universidade de Fortaleza (UNIFOR). Especialista em Direito e Processo Tributários pela Universidade de Fortaleza (UNIFOR). Graduado pela Universidade de Fortaleza (UNIFOR). Advogado. thiagose@ hotmail.com.

${ }^{2}$ Mestranda em Processo e Direito ao desenvolvimento pelo Centro Universitário Christus (UNICHRISTUS). Bolsista da Fundação Cearense de Apoio ao Desenvolvimento Científico e Tecnológico (FUNCAP). Especialista em Direito Processual Civil pela Faculdade Tecnológica de Palmas (FTP). Bacharel em Direito pela Universidade de Fortaleza (UNIFOR). stefani.scb@gmail.com.
} 
O presente estudo pretende abordar as teorias econômicas de John Maynard Keynes e Friedrich August Von Hayek, dois expoentes na pesquisa acerca dos ciclos econômicos, sob a perspectiva das políticas econômicas adotadas no Brasil pós-crise de 2008.

Inicialmente será abordada a vida e a obra desses dois economistas, tratando dos seus feitos e de suas grandes contribuições para a política e economia, que os fizeram ser mundialmente reconhecidos.

A pesquisa abrangerá os diferentes posicionamentos destes economistas. A teoria de Keynes sobre ciclos econômicos é mundialmente conhecida sendo chamada de Escola Keynesiana, enquanto Hayek com seus estudos acerca dos ciclos econômicos faz parte da Escola Austríaca de Economia em razão de seu pensamento econômico.

Será abordada também a crise mundial iniciada nos Estados Unidos em 2008 e de que forma causou impacto na economia e na sociedade brasileira, através da análise de gráficos relacionados ao crescimento do Produto Interno Bruto (PIB), taxa de juros, inflação, dentre outros também importantes para a compreensão da dimensão deste fenômeno econômico.

A partir deste panorama, será realizada uma análise a respeito das políticas econômicas utilizadas para que o país superasse a crise mundial, dividindo-se a abordagem em dois pontos principais.

O primeiro refere-se ao governo de 2008 até 2016, aonde ocorreu uma política de expansão monetária, com o Estado sendo um grande interventor na economia, barateando o crédito à população, através da queda da taxa de juros, bem como aumentando os gastos públicos, como forma de incentivar a retomada do crescimento econômico do país.

Esta política econômica de expansão monetária pode ser identificada como uma política pertencente a Escola Keynesiana do economista John Maynard Keynes, que acreditava em uma forte intervenção estatal na recuperação econômica de um país.

O segundo momento será o governo de 2016 até 2018, com a mudança na presidência, devido ao impeachment da ex-presidente Dilma Rousseff, ocorreu uma nova postura na política econômica do país.

O governo ao invés de aumentar os gastos públicos para retomar o crescimento do país, reduz os gastos públicos e inicia uma política de austeridade fiscal, com o objetivo de diminuir o déficit público e a inflação do país. 
O artigo pretende analisar as políticas econômicas até o ano de 2018, tendo em vista que, embora o atual governo esteja adotando, inicialmente, medidas que visem à austeridade fiscal, não é possível afirmar que esta será a política econômica adotada pelo seu governo.

O presente trabalho foi desenvolvido a partir de uma pesquisa quantitativa e qualitativa, valendo-se de pesquisas em livros sobre as teorias de ciclos econômicos dos autores e a análise de gráficos acerca da economia do país.

\section{JOHN MAYNARD KEYNES E A ESCOLA KEYNESIANA}

John Maynard Keynes nasceu em Cambridge, Inglaterra em 1883 e faleceu em Sussex, Inglaterra em 1946. Keynes foi um famoso economista britânico que com suas teorias, exerceu uma grande influência sobre a política econômica à época e influencia os estudos econômicos até os dias atuais (CARNEIRO, 1997).

Keynes exerceu funções no Departamento de Tesouro Britânico, sendo inclusive o representante financeiro daquele Departamento na Conferência da Paz. Entretanto, foi na vida acadêmica que Keynes conseguiu um maior destaque, sendo conhecido como um dos economistas mais famosos do mundo (DILLARD, 1993).

Na década de 1930, com suas obras $O$ tratado sobre a moeda e A teoria geral do emprego, do juro e da moeda, Keynes conseguiu alcançar uma maior relevância. O economista acreditava que a teoria econômica deveria ser um método para organizar o raciocínio sobre os problemas concretos enfrentados pela sociedade (DILLARD, 1993).

Após o fim da Primeira Guerra Mundial, Keynes escreveu a obra As consequências econômicas da guerra (1919) e A revisão do Tratado de Versalhes (1922), onde criticava as sanções econômicas impostas pelos vencedores à Alemanha. A ideia de Keynes é de que não seria possível produzir superávit capaz de honrar com os pagamentos exigidos pelos vencedores, sendo necessário - ao menos inicialmente - um financiamento externo para que houvesse uma taxa de câmbio mais favorável para que a Alemanha pudesse produzir superávits e pagar as sanções econômicas (DILLARD, 1993).

Keynes continuou o desenvolvimento de sua teoria que relacionava moeda, preços e taxa de câmbio e em 1923 escreveu a obra Ensaio sobre a reforma monetária. Nesta obra, Keynes defendia que o valor de uma moeda seria determinado principalmente pelo montante de bens e serviços possíveis de serem adquiridos no país emissor da moeda. E a taxa de 
câmbio revelaria a relação entre o poder de compra das duas moedas emitidas, sendo assim, a paridade ideal entre duas moedas seria aquela que equilibrasse o poder de compra interno ao externo dos países que emitiram a moeda (LIMA; SICSÚ, 2003).

De acordo com Keynes a alta valorização da libra, a época, era responsável pela deflação exagerada enfrentada pela Grã-Bretanha em 1925, o que desincentivava a produção, bem como estagnava a indústria. $\mathrm{O}$ economista defendia que gasto público deveria servir como incentivo para a retomada de investimentos em épocas em que a economia estivesse estagnada. (CARNEIRO,1997).

Estas preocupações de Keynes o levaram a produzir a obra $O$ tratado sobre a moeda (1930) e poucos anos depois escreveu a obra A teoria do emprego, do juro e da moeda (1936). Estas obras são as principais teorias desenvolvidas por John Maynard Keynes e a consolidação destes pensamentos econômicos ficou conhecida como Escola Keynesiana, que será abordada a seguir.

\subsection{Escola Keynesiana}

A Escola Keynesiana ou o Keynesianismo é a consolidação da teoria econômica desenvolvida pelo economista britânico John Maynard Keynes. Em linhas gerais, este pensamento econômico é oposto às ideias liberais e entende que o Estado exerce um papel fundamental na economia, devendo ser um fomentador de investimentos com o objetivo de conduzir o país ao pleno emprego. (CARNEIRO, 1997).

Esta condição de colocar o Estado como um agente indispensável na intervenção da economia do país teve uma enorme influência na reformulação da política econômica mundial. Vale ressaltar o contexto histórico do surgimento da Escola Keynesiana, que se deu após a Grande Crise de 1929, tendo em vista que sua obra, O tratado sobre a moeda, foi publicada em 1930 (LIMA; SICSÚ, 2003).

Keynes (1985) não acreditava no pensamento dominante a época, que era os da teoria clássica - assim denominados por Karl Marx. O economista argumenta em sua teoria que "os postulados da teoria clássica se aplicam apenas a um caso especial e não ao caso geral, pois a situação que ela supõe acha-se no limite das possíveis situações de equilíbrio" (KEYNES, 1985, p. 15). 
Keynes (1985) afastava a ideia de que a economia era auto regulável, como defendiam os economistas da teoria clássica, devendo o Estado tomar medidas fiscais e monetárias para garantir o pleno emprego. Apesar de criticar o liberalismo econômico, o economista não era a favor da estatização da economia, como ocorria nos modelos de economia socialista.

Em situações de crise, o economista britânico argumentava que o Estado deveria desempenhar um papel fundamental nos investimentos, para fortalecer a economia e gerar empregos, o que estimularia o consumo e faria a economia se recuperar, pois não seria possível esta recuperação sem a forte atuação estatal. (CARNEIRO, 1997).

O pensamento econômico de Keynes foi a base para o plano de recuperação da economia americana na crise de 1929 , denominado de New Deal ${ }^{3}$ (Novo Acordo) no governo do presidente Roosevelt.

Após a Segunda Guerra Mundial, o Keynesianismo ganhou força, sendo aderida pela maior parte dos países capitalistas do mundo. Na década de 70 sofre severas críticas pelos economistas liberais, somente voltando a ganhar força na crise mundial de 2008 (DILLARD, 1993).

Um de seus principais críticos foi o economista austríaco Friedrich August von Hayek, vencedor do prêmio Nobel de economia de 1974 pela sua teoria de ciclos econômicos, que será debatido com mais ênfase no capítulo seguinte.

\section{A TEORIA ECONÔMICA DE FRIEDRICH AUGUST VON HAYEK}

Friederich August Von Hayek nasceu em Viena, Austrália em 8 de maio de 1899 e faleceu aos 92 anos em 23 de março de 1992 na cidade de Friburgo, Alemanha. Atuou como professor na London School of Economics (Escola de Economia de Londres) e tornou-se um dos economistas mais renomados do mundo na década de 30, embora sua pouca idade. (BOUDREAUX, 2017).

A fama de Hayek se expandiu principalmente pela sua pesquisa acerca das causas dos ciclos econômicos, ou seja, sobre o crescimento e a recessão da economia. É importante

\footnotetext{
${ }^{3}$ O New Deal foi uma série de programas econômicos elaborados pelo governo do presidente americano Franklin Roosevelt, que objetivava a recuperação econômica dos Estados Unidos pós-crise de 1929. O New Deal tomou medidas como o investimento em obras públicas, destruição do estoque excedente da produção agrícola, criação do salário mínimo e a diminuição da jornada de trabalho, dentre outras medidas (PINTO, [201?]).
} 
ressaltar o contexto histórico em que pesquisa estava sendo desenvolvida, logo após a Grande Depressão ocorrida em 1929 (BOUDREAUX, 2017).

O seu objetivo era estudar os motivos que as crises econômicas aconteciam para evitar que o mundo sofresse com novas crises, que prejudicavam principalmente os mais pobres da sociedade.

Hayek tinha como principal opositor o economista Keynes, que defendia a ideia de que mesmo as maiores recessões poderiam ser solucionadas com o aumento do gasto público, enquanto Hayek refutava esta ideia ao argumentar que não existiam soluções fáceis para resolver uma economia em declínio (GENNARI, 2009).

O economista austríaco afirmava que o aumento de gastos públicos tão somente iria adiar a crise econômica para um momento posterior que seria ainda mais gravosa no futuro e que demoraria ainda mais tempo para que a economia pudesse se recuperar, sendo assim, o aumento de gasto público iria inicialmente dar impressões de que a economia estaria se recuperando, entretanto isto não passaria somente de uma ilusão, que teriam gravosas consequências ao longo do tempo (GENNARI, 2009).

A teoria de Keynes, denominada Escola Keynesiana, como já fora discutido anteriormente, foi amplamente aceita a época, sendo Hayek e sua teoria sobre ciclos econômicos ficando esquecidos.

Somente em 1944, no auge da Segunda Guerra Mundial, com a publicação da obra $O$ Caminho da Servidão (1944), Hayek ganhou novamente visibilidade. Esta obra, que fora um best-seller a época, alerta sobre os perigos da planificação da economia ou mesmo da tentativa do Estado em proteger os cidadãos, em situações de mudanças econômicas. Hayek denominou esta intervenção de "caminho de servidão", onde demonstrou que quando o governo planifica ou regula em demasiado a economia consequentemente privará também os cidadãos de inúmeras liberdades, sendo assim os cidadãos trilhariam um caminho de servidão, que deu intitulou a obra (GENNARI, 2009).

O economista austríaco defendia a tese de que quanto maior a intervenção governamental na economia, mais direitos dos cidadãos seriam suprimidos e, não, que ao menor sinal de regulamentação haveria a manifestação do socialismo e da tirania (BOUDREAUX, 2017).

$\mathrm{Na}$ década de 50 o economista austríaco mudou-se para a Universidade de Chicago, Estados Unidos, onde continuou a produzir outras obras como A Constituição da Liberdade 
(1960) e também a obra em três volumes Direito, Legislação e Liberdade (publicada nos anos de 1970) (BOUDREAUX, 2017).

Em 1974, finalmente teve o devido reconhecimento pelos seus estudos e pesquisas na área econômica, sendo premiado com o Nobel de Economia por conta de sua teoria sobre os ciclos econômicos (BOUDREAUX, 2017).

A última obra do autor foi publicada em 1988, denominada Os Erros Fatais do Socialismo. O Nobel de economia faleceu aos 92 anos em Friburgo, Alemanha em 1992. (BOUDREAUX, 2017)

\subsection{Escola Austríaca de Economia}

A Escola Austríaca de Economia é uma das correntes econômicas mais importantes e que surgiu em meados do século XIX. O principal pensador desta corrente é o austríaco Ludwing von Mises.

Hayek foi aluno de Mises e foi muito influenciado pela obra publicada pelo seu orientador "Socialismo: Fundamentos Econômicos e Sociológicos" (1922), em seus estudos sobre os ciclos econômicos, o que levou Hayek a ser premiado com o Nobel de economia em 1974. Defendia, então, a ideia de que a economia era muito complexa e não seria possível um governo central tomar decisões efetivas sobre planejamento econômico (GENNARI, 2009).

O economista afirmava também que os preços dos produtos/serviços possuíam justamente fornecem as informações necessárias para que a sociedade planeje sua vida. (BOUDREAUX, 2017). Em suma, se o preço de um produto/serviço aumenta significa que há um desequilíbrio entre demanda e oferta, o que fará com que haja um maior investimento para suprir a necessidade daquela demanda existente.

E com isto, ao passar do tempo, a tendência é que haja um equilíbrio entre demanda e oferta existindo um equilíbrio nos preços. E que uma interferência de um Governo Central faz com que os preços sejam distorcidos e não haja uma informação precisa acerca da demanda e oferta de determinado mercado consumidor.

Hayek foi o grande opositor de Keynes, afirmando que, a ideia de o Estado injetar dinheiro na economia, sem que houvesse poupança para tal, fazendo isto através de uma expansão monetária, poderia gerar no início uma falsa sensação de que a economia estaria se recuperando, entretanto as consequências viriam ao longo dos anos, através de uma alta inflacionária (com a moeda sendo desvalorizada) e o aumento da dívida do Estado, o que 
colocaria esta economia em uma situação ainda mais complicada do que estava anteriormente (BOUDREAUX, 2017).

Através dos pensamentos econômicos de Keynes e Hayek será abordada a crise econômica de 2008 e os seus impactos no Brasil, bem como as políticas econômicas utilizadas no país pós-crise.

\section{A CRISE ECONÔMICA DE 2008}

A crise econômica de 2008 iniciou nos Estados Unidos da América e teve seu apogeu com a falência do banco americano Lehman Brothers ${ }^{4}$, que era um tradicional banco de investimento americano, tendo sido fundado em 1850 (BBC BRASIL, 2008).

A falência do banco levou ruína de outras instituições financeiras. Este período também foi denominado de crise do subprime. Em suma, esta crise ocorreu devido a uma crise imobiliária de proporções inimagináveis.

O FED (Federal Reserv System), o Sistema de Reserva Fiscal Americano, com o objetivo de estimular a economia do país, reduziu a taxa de juros como forma de tornar os empréstimos mais baratos e incentivar o financiamento de imóveis.

O governo americano ainda garantiu os investimentos realizados pelas empresas Fannie Mae e da Freddie Mac, intermediárias no financiamento imobiliário. Tais medidas levaram a uma grande procura de imóveis, fazendo com que o preço aumentasse, devido à grande demanda (PRESSE, 2008).

Os americanos procuravam cada vez mais financiamentos e os intermediários ao buscar os lucros não tiveram critério para aprovar financiamentos e as instituições financeiras confiaram que os pagamentos seriam honrados devido a baixa taxa de juros (PRESSE, 2008).

Entretanto a piora da economia americana forçou o governo americano a aumentar a taxa de juros, o que levou a um aumento do valor do financiamento de muitos imóveis.

Devido a isto, a inadimplência no país aumentou bastante, levando à falência muitas instituições financeiras que tinham financiado estes imóveis, ocorrendo um verdadeiro efeito

\footnotetext{
${ }^{4}$ Cf. BBC Brasil: <https://economia.uol.com.br/ultnot/bbc/2008/09/15/ult2283u1332.jhtm>.
} 
dominó, que teve consequências mundiais no crescimento econômico de muitas nações, onde muitas ainda não se recuperaram totalmente (CURY, 2013).

O Brasil foi uma destas economias que foram muito afetadas pela crise econômica e, que por uma série de fatores que serão abordados a seguir, ainda enfrenta dificuldades para retomar o rumo do desenvolvimento.

\subsection{O impacto da crise econômica no Brasil}

A crise econômica teve um forte impacto na economia brasileira, levando a uma série de consequências para o país, como a alta da inflação, recessão, aumento do desemprego, dentre outros inúmeros problemas econômicos com consequências gravosas na economia do Brasil. O auge da crise econômica ocorreu com a falência do banco americano Lehman Brothers ${ }^{5}$. A partir deste fato, investidores do mundo inteiro iniciaram a retirar seus investimentos de ações de empresas, de bancos e títulos do governo, e isto incluiu o Brasil (BBC BRASIL, 2008).

Este fato fez com que houvesse uma significativa redução da concessão de créditos no Brasil, afetando empresas e consumidores. As empresas tiveram dificuldades em conseguir crédito para aumentar o seu investimento em seus negócios, enquanto os consumidores dificuldades ao financiar carros e imóveis, prejudicando a economia do país (GASPARIN, 2011).

Como forma de estimular a economia, o governo brasileiro tomou uma série de medidas para estimular a economia e aumentar o crédito no país. Uma das medidas do governo foi a drástica redução da taxa de juros.

Em dezembro de 2008 a taxa Selic era de 13,75\% e em julho de 2009 já tinha caído para 8,75\%, uma expressiva queda de 5\% em 7 meses, levando a menor taxa de juros da última década (BANCO CENTRAL DO BRASIL, 2019).

O país sofreu também com o baixo crescimento, tendo um crescimento negativo de 0,1\% em 2009, que através dos estímulos do governo teve uma boa recuperação crescendo 7,5\%, em 2010 (IBGE, 2019).

\footnotetext{
${ }^{5}$ Cf. BBC Brasil: <https://economia.uol.com.br/ultnot/bbc/2008/09/15/ult2283u1332.jhtm>.
} 
GRÁFICO 1 - Crescimento \% Produto Interno Bruto (PIB) - Brasil

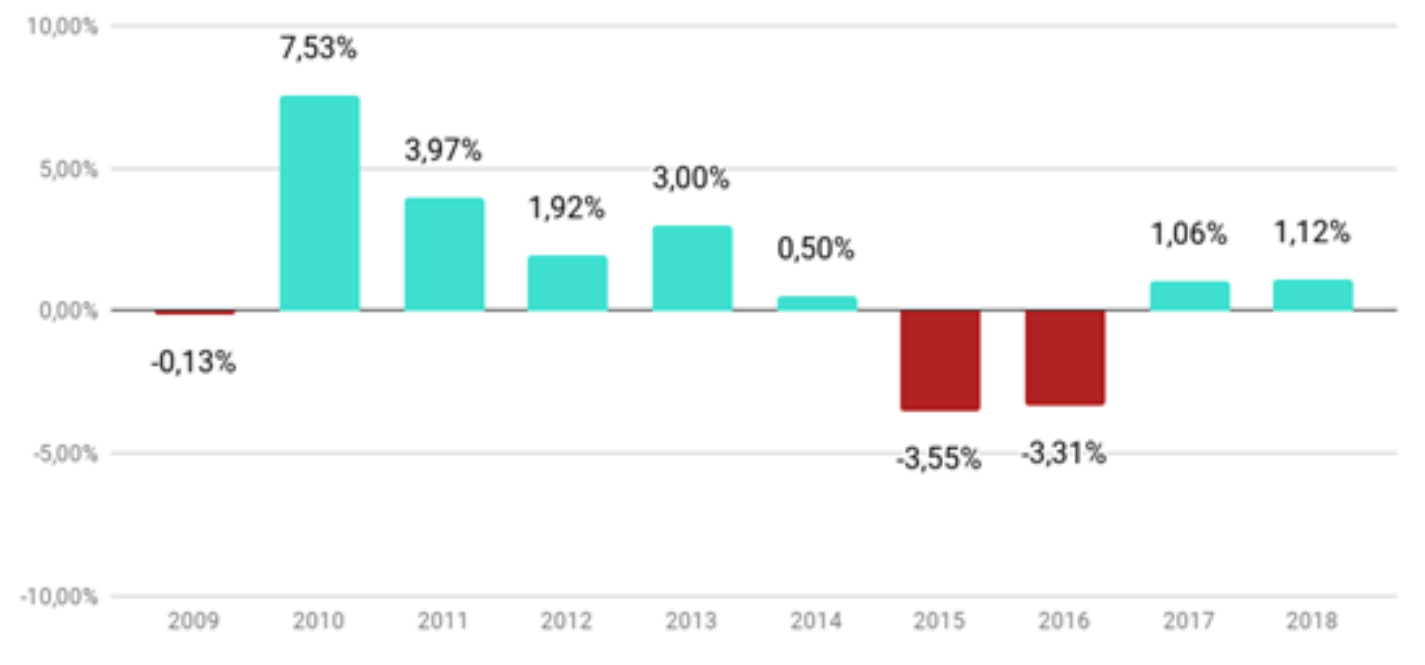

Fonte: GAZETA DO POVO (PIB..., 2019)

Entretanto, como se percebe pelo gráfico acima, esse crescimento do país não foi duradouro, de modo que seu crescimento nos anos seguintes, fora cada vez menor, culminando, assim, em uma forte recessão.

A partir disto, será analisada a política econômica do Brasil pós-crise de 2008 e os pensamentos da Escola Keynesiana e da Escola Austríaca que foram e estão sendo aplicadas na economia brasileira, como forma de resolver o problema da crise econômica enfrentada desde 2008.

\section{A POLÍTICA ECONÔMICA PÓS-CRISE DE 2008}

Após o país ter ficado estagnado no ano de 2009, o governo tomou uma série de medidas para estimular a economia, seguindo o que pregava a teoria Keynesiana, qual seja, um Estado interventor na economia, principalmente em épocas de grandes crises econômicas.

Krugman (2009) afirma que, para enfrentar a crise, "os formuladores de política em todo o mundo precisam fazer duas coisas: garantir o fluxo de crédito e, mais uma vez, estimular os gastos".

A solução mais recomendada de forma imediata seria, portanto, a injeção de capital na economia, entretanto o próprio autor confirma ter dúvidas se somente esta medida seria suficiente para solucionar a crise, defendendo uma intervenção ainda mais forte na economia por parte do Estado, dispondo que seria necessária a promoção da recapitalização maior e 
mais ampla, em um primeiro momento, e, em seguida, dar mais ênfase ao controle estatal, aproximando-se de uma estatização plena e temporária de parcela considerável do sistema financeiro (KRUGMAN, 2009).

Diante disto, analisar-se-á as medidas econômicas de intervenção na economia por parte do Estado a partir da crise de 2008, que pode ser dividida entre dois momentos.

Inicialmente, vislumbra-se uma forte intervenção estatal na economia, ou seja, injeção de capital, através da queda da taxa de juros, bem como um maior gasto público, conforme defendeu Krugman.

Este primeiro momento durou desde a crise de 2008 até meados de 2016, quando a ex-presidente Dilma Rousseff sofreu um processo de impeachment e foi afastada do cargo da Presidência da República.

O segundo momento se deu desde o início do governo de Michel Temer, onde houve uma profunda mudança na política econômica do país, destacando-se o controle dos gastos públicos, através da Proposta de Emenda Constitucional n ${ }^{\circ} 55 / 2016^{6}$, conhecida como "PEC do teto de gastos", que limitou os gastos públicos do governo federal.

O governo brasileiro, diante da crise econômica, entendeu ser necessário que o Estado fosse atuante para que o país pudesse retomar o desenvolvimento, tendo em vista a recessão de $0,1 \%$ ocorrida no PIB em 2009.

Pode-se citar como interferências promovidas pelo ente estatal na economia: o subsídio da energia e do combustível, forçando com que estes preços não subissem para não pressionar a inflação, linha branca IPI, dentre outras ações do governo na tentativa de estimular a economia do país (DW BRASIL, 2017).

Inicialmente os estímulos deram certo com o país crescendo 7,5\% em 2010, porém o crescimento do país foi minguando até chegar em 2014 tendo um crescimento de somente 0,50\%. Após isto, o Brasil iniciou um período de forte recessão em sua economia tendo uma recessão de 3,55\% e 3,31\% nos anos de 2015 e 2016, respectivamente (DW BRASIL, 2017).

Para isto, reduziu a taxa de juros, como forma de estimular o crédito e incentivar os gastos, conforme se observa no gráfico abaixo.

Cf. Emenda Constitucional $\mathrm{n}^{\mathrm{o}}$ 55, de 15 dezembro de 2016. Disponível em: <https://www25.senado.leg.br/web/atividade/materias/-/materia/127337>. 
GRÁFICO 2 - Taxa de juros no Brasil

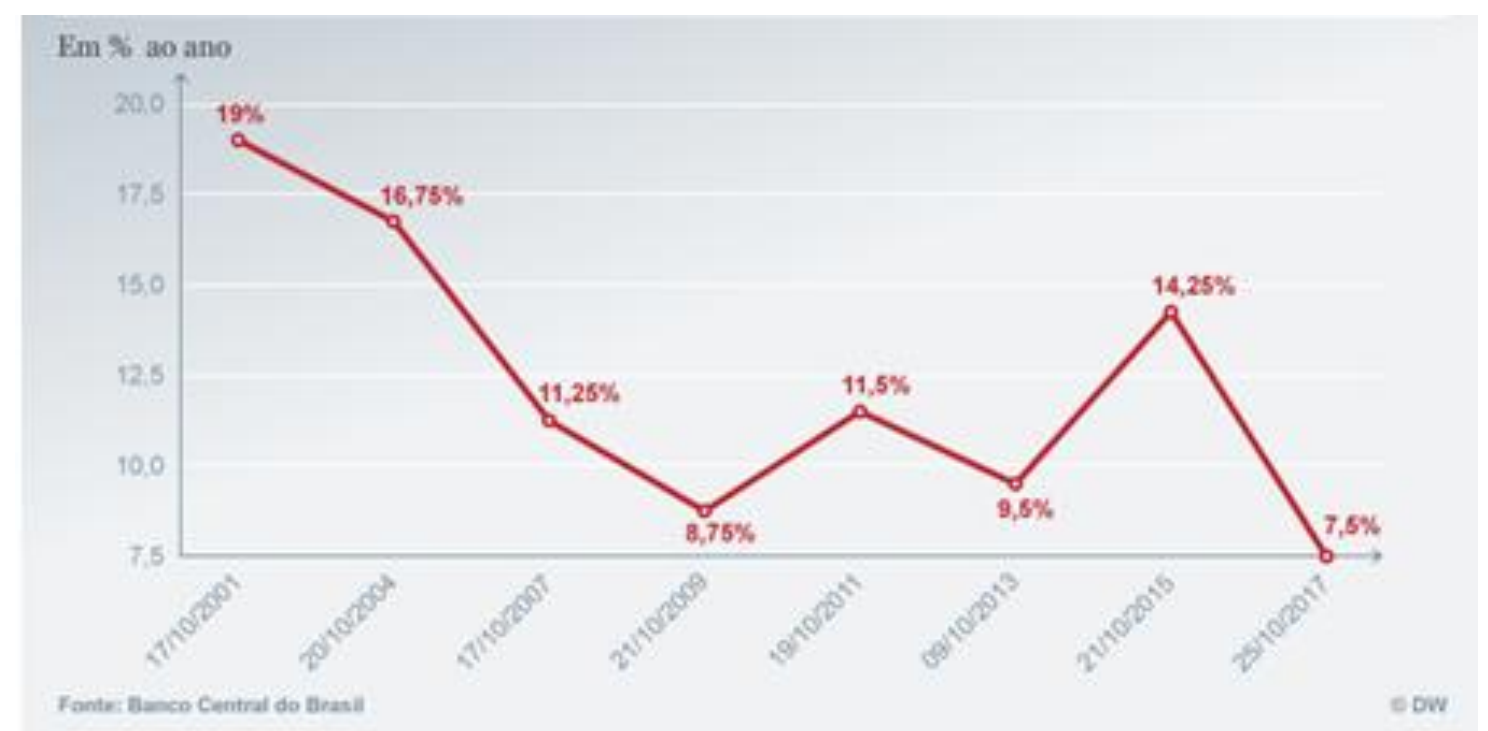

Fonte: DW BRASIL (2017)

Entretanto, essa queda forçada da taxa de juros refletiu na inflação do país, que se elevou no ano de 2010, fazendo com que o governo novamente elevasse a taxa de juros numa tentativa de controlar a inflação, como se percebe no gráfico abaixo.

\section{GRÁFICO 3 - A inflação brasileira}

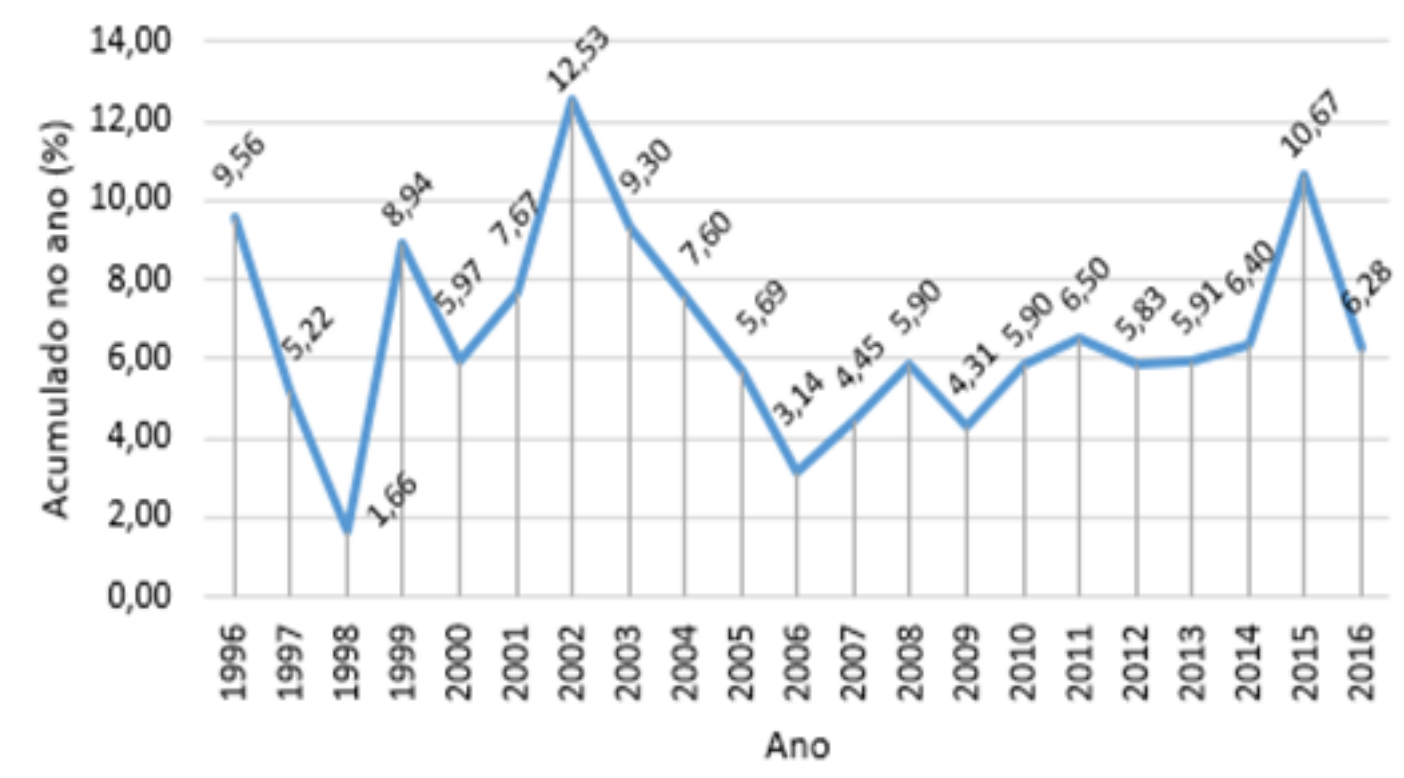

Fonte: IBGE (2019)

Ocorre que analisando o gráfico acima, a medida do governo em aumentar a taxa de juros não surtiu um efeito tão imediato e não foi tão impactante no controle inflacionário do 
país, ao mesmo tempo em que o crescimento do PIB, de acordo com o Gráfico 1, estava em decadência.

O descontrole inflacionário pode ser explicado por conta do aumento exponencial dos gastos públicos governamentais, que teve um expressivo aumento ao longo dos anos, póscrise de 2008, como forma de estimular o crescimento do país, o que funcionou bem nos primeiros anos pós-crise.

No gráfico abaixo, é possível analisar a evolução das despesas primárias da União, ou seja, as despesas efetuadas pelo Governo Federal antes de pagar os juros da dívida pública.

GRÁFICO 4 - Despesas primárias do Governo Federal (\% PIB)

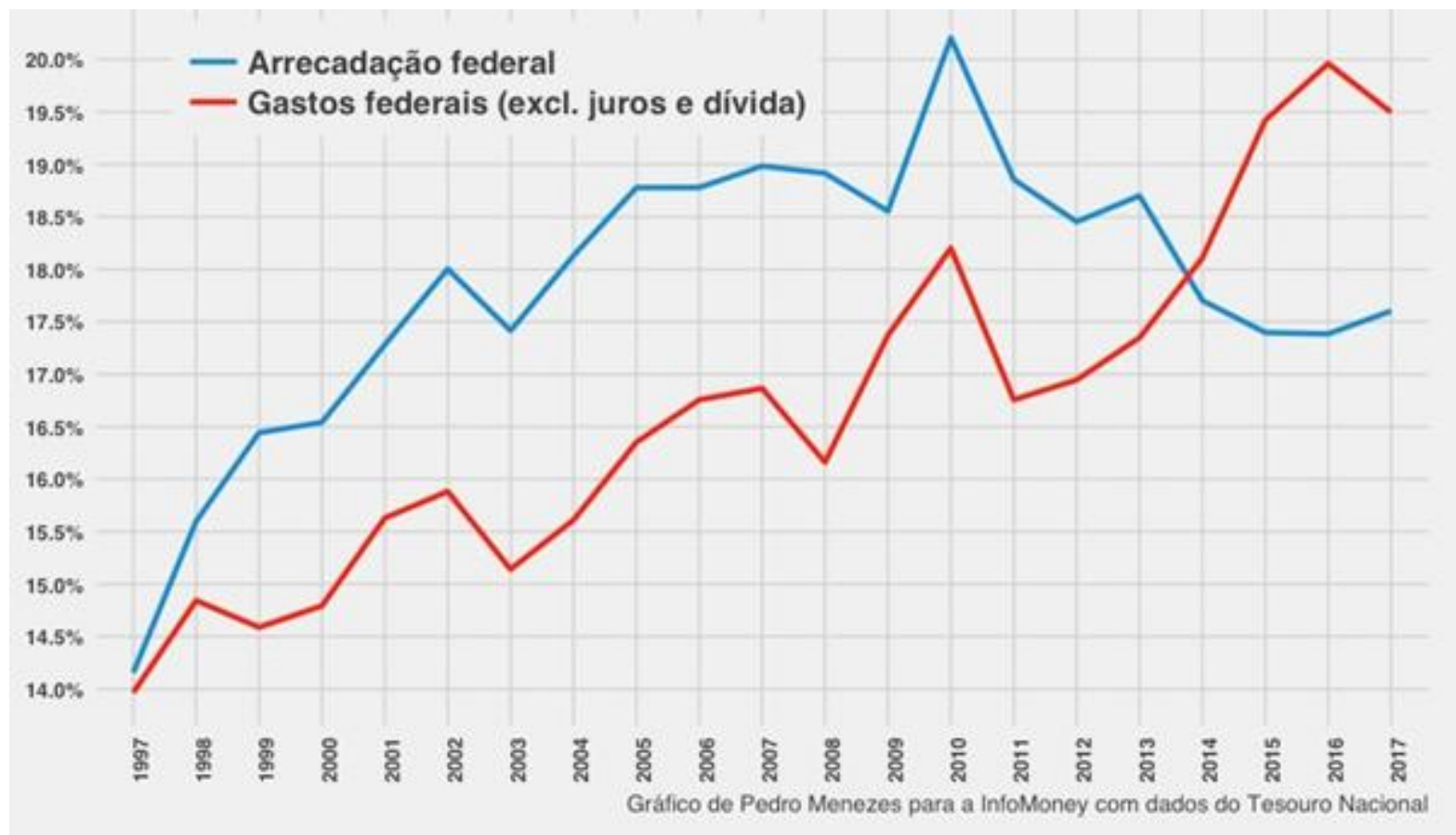

Fonte: Tesouro Nacional (MENEZES, 2018) 
Devido ao aumento dos gastos públicos, o país iniciou a ter sucessivos déficits fiscais, por não ter condições financeiras de arcar com todos os gastos governamentais, conforme pode ser analisado no gráfico abaixo.

\section{GRÁFICO 5 - Resultado das Contas Públicas do Governo Federal}

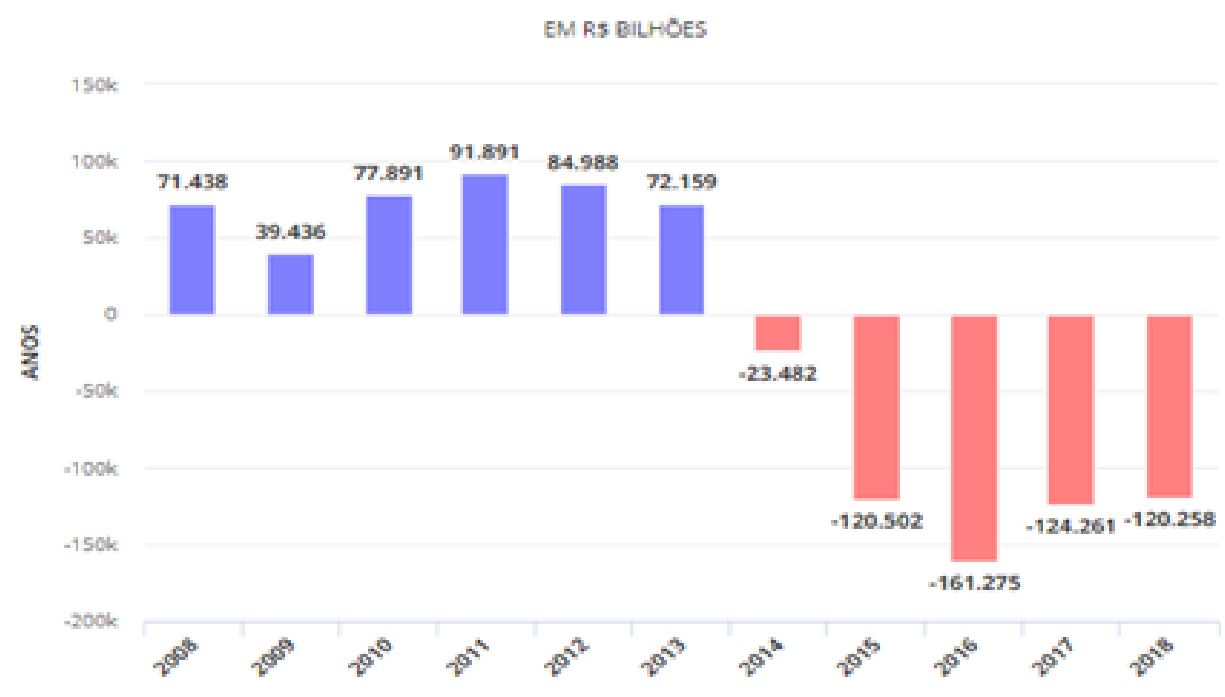

Fonte: G1 (MARTELLO, 2019a)

Os sucessivos aumentos no déficit fiscal trouxeram como consequência um significativo aumento da dívida pública brasileira, o que fez com que o país sofresse uma crise de confiança do mercado internacional, sendo rebaixado por agências de risco internacional, que medem a confiabilidade em investir no país.

\section{GRÁFICO 6 - DÍVIDA BRUTA DO BRASIL (\% PIB)}

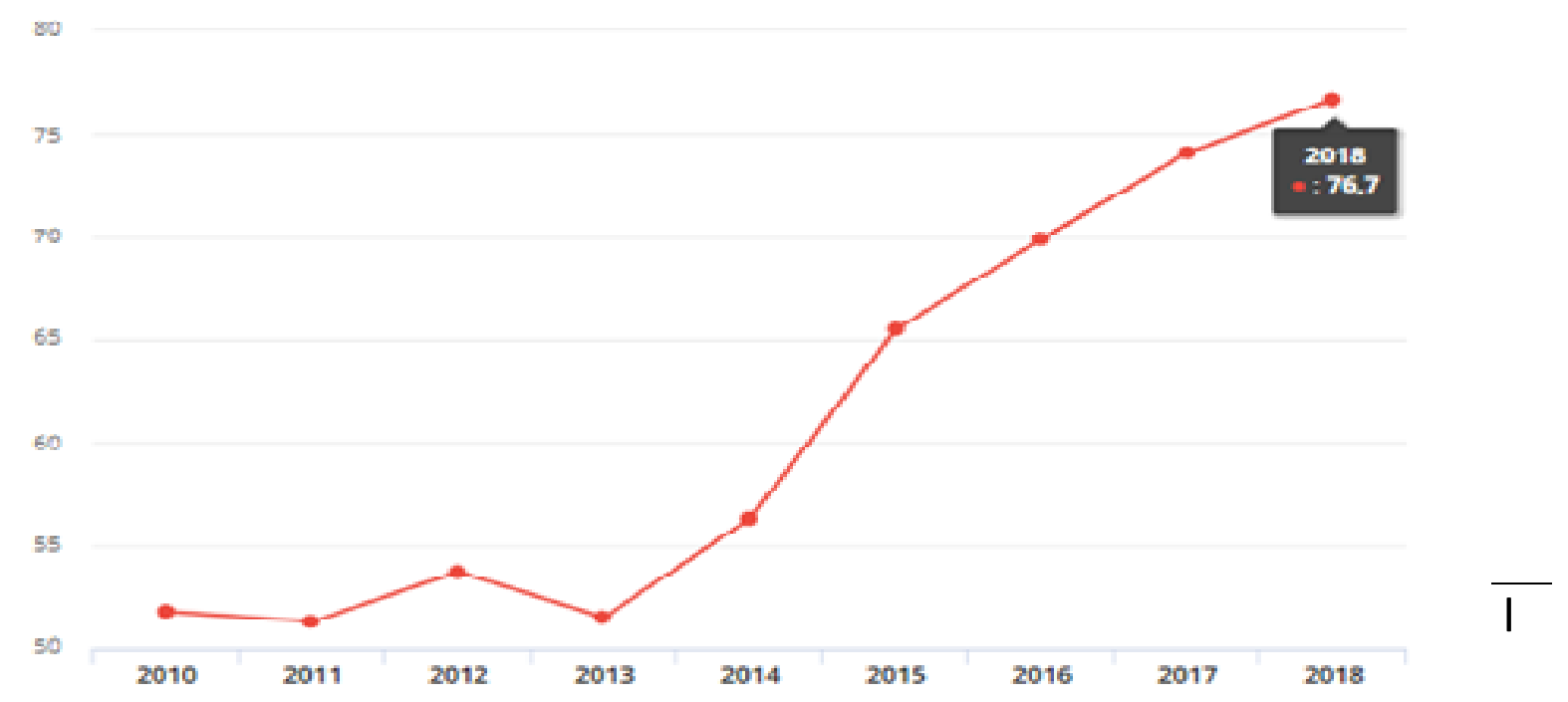


Fonte: G1 (MARTELLO, 2019b)

Pode ser citado como exemplo o rebaixamento da nota (de BBB- para BB+) dada pelas agências de classificação de risco: Standard \& Poor's e Fitch, fazendo com que o país perdesse o selo de bom pagador, o que significa que investir no Brasil tornou-se mais arriscado, devido ao descontrole fiscal afastando, portanto, investimentos internacionais (SCIARETTA; LANDIM, 2015; MENDONÇA, 2015).

O auge da crise econômica do país foi em 2015 quando mesmo com uma alta taxa de juros de 14,25\% (Gráfico 2), o país teve uma inflação de 10,67\% (Gráfico 3) e ainda teve uma recessão de $3,55 \%$, chegando ao patamar de estagflação ${ }^{7}$.

Além da grave crise econômica que o país enfrentava, a ex-presidente Dilma Rousseff também passava por uma grave crise política, em razão de denúncias de corrupção em seu governo, o que culminou em seu impeachment.

A mudança de governo iniciou uma nova era na política econômica do país, assumindo o então presidente Michel Temer. Estas mudanças na política econômica do país tiveram como objetivo garantir uma maior austeridade fiscal nas contas públicas do governo, o oposto do que o governo passado esta realizando, que seguia as teorias de Keynes.

A política econômica de controle dos gastos públicos segue o pensamento de Hayek e da Escola Austríaca de Economia, que será debatido com maior profundidade a seguir.

\subsection{A política econômica de austeridade fiscal (2016-2018)}

O novo governo iniciou com o objetivo de controlar os gastos públicos e a inflação, defendendo a ideia de que somente injetar dinheiro na economia e aumentar os gastos públicos não seriam medidas efetivas para a recuperação econômica, pelo contrário, de início poderia até melhorar a situação do país, entretanto a longo prazo o país se aprofundaria em uma crise maior do que já estava.

Esta ideia de que a poupança de um país era importante e que a interferência estatal na economia seja através de estímulos de créditos seja através de um expressivo aumento de gasto público provocaria uma crise ainda mais gravosa ao longo prazo faz parte do

\footnotetext{
${ }^{7}$ Termo utilizado para definir a situação econômica em que ocorre simultaneamente estagnação e inflação.
} 
pensamento econômico de Friederich August Von Hayek, que foi premiado com o Nobel de Economia em 1974, pelos seus estudos de ciclos econômicos.

Uma das medidas mais importantes realizadas pelo governo de Michel Temer foi a Proposta de Emenda Constitucional n 55 , que foi denominada de "PEC do teto de gastos".

Essa Proposta de Emenda Constitucional, que foi aprovada pelo Congresso teve como objetivo limitar os gastos públicos federais. E esta medida surtiu efeito, como pode ser analisado através do Gráfico 5 o déficit público de 2017 foi inferior ao de 2016. E em 2018 o déficit público foi ainda diminuiu.

As medidas econômicas de controle de gasto público fizeram com que o país tivesse uma melhora econômica com o Produto Interno Bruto nacional, retornando ao crescimento, a inflação do país sendo controlada e a taxa de juros sendo reduzida de forma gradual.

Entretanto, tais medidas não foram suficientes para o país iniciar uma forte recuperação econômica, tendo em vista que, por mais que a inflação fosse controlada e se atingisse a menor taxa de juros da história, não foi possível um crescimento econômico acelerado (VALENTE, 2018).

Vale ressaltar que as medidas econômicas tomadas pelo governo do Michel Temer, por mais que tenham aumentado o controle fiscal dos gastos, não foram suficientes para livrar o país de sucessivos déficits públicos, em parte, consequência do déficit previdenciário.

\section{GRÁFICO 7 - Resultado do RGPS e do Governo Federal}

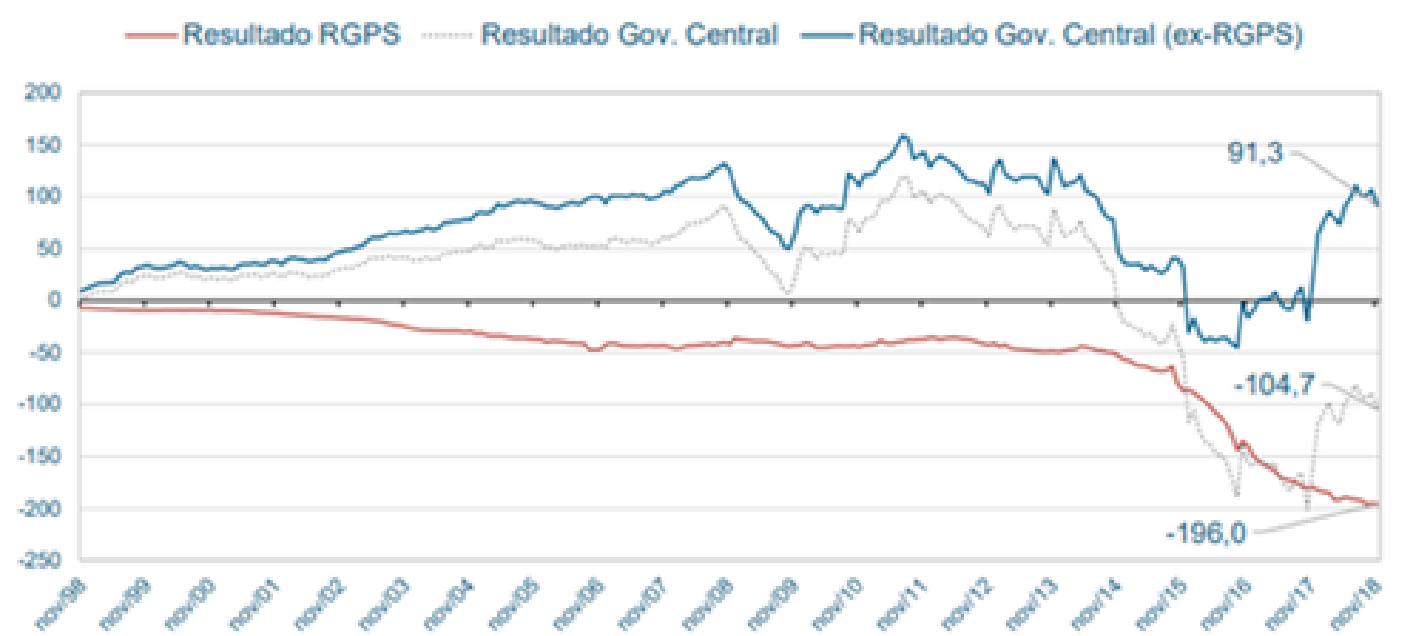

Fonte: Gráfico elaborado pelo Instituto Fiscal Independente (SALTO, 2019)

Pelo gráfico acima é possível observar que, se o país tivesse um controle ordenado dos gastos previdenciário, seria possível encerrar o ano fiscal com o superávit, entretanto esta 
ainda não é uma realidade do país. E a Reforma Previdenciária pode beneficiar as contas públicas brasileiras, porém não terão grandes efeitos em um curto-médio prazo, o que significa que o país ainda necessita manter o controle de gastos públicos e a política de austeridade fiscal.

Pela teoria da Escola Austríaca de Economia, o Brasil está no rumo certo de um crescimento saudável, com gastos controlados, bem como com a sua inflação e taxas de juros equilibradas.

\section{CONCLUSÃO}

No presente estudo, ao se analisar as políticas econômicas praticadas no país póscrise de 2008, pode-se perceber que foram utilizadas duas teorias distintas que, há décadas, causam conflitos entre os economistas que estudam os ciclos econômicos.

É inegável que a teoria de Keynes, onde o Estado exerce um papel essencial na retomada do crescimento econômico do país e que foi utilizado no país entre 2008 e 2016, foi responsável pelo aquecimento da economia do Brasil, tendo um crescimento de 7,53\% em 2010.

Entretanto, ao longo dos anos, este crescimento não se mostrou sustentável e o país aprofundou a sua crise econômica, através de um alto endividamento, recessão, inflação alta, que nem mesmo os altos juros foram capazes de contê-la.

A pós-crise de 2008 do Brasil se prolongou, fazendo com que o país ficasse em um estado de estagflação, situação econômica de recessão e alta inflacionária, o que resultou em uma situação difícil para o país.

A política econômica da austeridade fiscal, entre os anos de 2016-2018, provocou uma lenta recuperação econômica do país, entretanto foi possível controlar a inflação, reduzir o déficit público e diminuir a taxa de juros.

Desta forma, conclui-se, pelo corte temporal existente que a teoria de Hayek, da Escola Austríaca de Economia, pode trazer uma recuperação mais lenta da economia do país, entretanto esta recuperação ocorre de maneira saudável, de acordo com os índices econômicos apontados. 


\section{REFERÊNCIAS}

BANCO CENTRAL DO BRASIL. Taxas de juros básicas: Histórico. Banco Central do Brasil [site], 2019. Disponível em: <

https://www.bcb.gov.br/controleinflacao/historicotaxasjuros>. Acesso em: 10 ago. 2019.

BBC BRASIL. Entenda a quebra do banco Lehman Brothers. UOL [site], Economia, 15 set. 2008. Disponível em:

$<$ https://economia.uol.com.br/ultnot/bbc/2008/09/15/ult2283u1332.jhtm>. Acesso em: 08 ago. 2019.

BRASIL. Congresso. Câmara dos Deputados. A crise financeira mundial e seu impacto no Brasil. Brasília: Câmara dos Deputados, 2009.

BRASIL. Constituição Federal (1988). Emenda Constitucional n ${ }^{\circ}$ 55, de 15 dezembro de 2016. Disponível em: <https://www25.senado.leg.br/web/atividade/materias//materia/127337>. Acesso em: 03 jun. 2019.

BOUDREAUX, Donald J. Menos Estado e Mais Liberdade. Tradução de Leonardo Castilhone. Barueri: Faro Editorial, 2017.

CARNEIRO. Ricardo. Os clássicos da Economia. São Paulo: Editora Ática. 1997.

CURY, Anay. Entenda a crise da dívida dos EUA e suas consequências. G1 [site], Economia, 16 out. 2013. Disponível em:

<http://g1.globo.com/economia/noticia/2013/10/entenda-crise-da-divida-dos-eua-e-suasconsequencias.html>. Acesso em: 12 ago. 2019.

DILLARD, Dudley. A teoria econômica de John Maynard Keynes: teoria de uma economia monetária. Tradução de Albertino Pinheiro Junior. 7. ed. São Paulo: Pioneira, 1993.

DW BRASIL. A baixa histórica dos juros no Brasil. DW Made for Mindes [site], 06 dez. 2017. Disponível em: <https://www.dw.com/pt-br/a-baixa-hist\%C3\%B3rica-dos-juros-nobrasil/a-41672969>. Acesso em: 03 jun. 2019.

GASPARIN, Gabriela. Entenda como a crise de 2008 influenciou a vida dos brasileiros. G1 [site], Economia, 15 set. 2011. Disponível em: <http://g1.globo.com/economia/seudinheiro/noticia/2011/09/entenda-como-crise-de-2008-influenciou-vida-dos-brasileiros.html>. Acesso em: 12 ago. 2019.

GENNARI, Adilson Marques; OLIVEIRA, Roberson de. História do pensamento econômico. São Paulo: Saraiva, 2009.

INSTITUTO BRASILEIRO DE GEOGRAFIA E ESTATÍSTIA. PIB a preços de mercado: Taxa acumulada em 4 trimestres (\%), $1^{\circ}$ trimestre 1996 - $2^{\circ}$ trimestre 2019. IBGE [site], 2019. Disponível em: <https://www.ibge.gov.br/estatisticas/economicas/contas-nacionais/9300contas-nacionais-trimestrais.html $?=\& \mathrm{t}=$ series-historicas $>$. Acesso em: 03 jun. 2019. 
INSTITUTO FISCAL INDEPENDENTE. Contas públicas no Brasil - Insper. Disponível em: <https://www12.senado.leg.br/ifi/publicacoes-1/apresentacoes-e-outrosdocumentos/2019/janeiro/contas-publicas-no-brasil-insper>. 28 jan. 2019. Acesso em: 05 jun. 2019.

KEYNES. John Maynard. A teoria geral do emprego, do juro e da moeda. 2ed. São Paulo: Nova Cultural, 1985.

KRUGMAN, Paul R. A crise de 2008 e a economia da depressão. Tradução de Afonso Celso da Cunha Serra. 3 ed. Rio de Janeiro: Elsevier, 2009.

LIMA, Gilberto Tadeu; SICSÚ, João. Macroeconomia do emprego e da renda: Keynes e o keynesianismo. São Paulo: Manole, 2003.

MARTELLO, Alexandro. No $5^{\circ}$ ano seguido de rombo, contas do governo têm déficit de R\$ 120 bilhões em 2018: Resultado, que ficou abaixo da meta fiscal, foi influenciado por alta na arrecadação de impostos e de royalties do petróleo. Déficit do INSS em 2018 foi de R\$ 195,2 bilhões. G1 [site], Economia, 29 jan. 2019. Disponível em: < https://g1.globo.com/economia/noticia/2019/01/29/contas-do-governo-tem-rombo-de-r-120bilhoes-em-2018.ghtml>. Acesso em: 05 jun. 2019.

MARTELLO, Alexandro. Contas do setor público registram rombo de $\mathbf{R} \$ 108$ bilhões em 2018: Esse foi o quinto ano seguido com as contas no vermelho, mas a meta fiscal foi atingida. Dívida bruta do setor público somou 76,7\% do PIB em dezembro. G1 [site], Economia, 31 jan. 2019. Disponível em: < https://g1.globo.com/economia/noticia/2019/01/31/contas-do-setor-publico-registram-rombode-r-108-bilhoes-em-2018.ghtml>. Acesso em: 05 jun. 2019.

MENDONÇA, Heloísa. Agência Fitch retira o selo de bom pagador do Brasil. El País, 16 dez. 2015. Disponível em:

<https://brasil.elpais.com/brasil/2015/12/16/economia/1450278719_673251.html>. Acesso em: 05 jun. 2019.

MENEZES, Pedro. Entenda em 5 gráficos por que você precisa perder "direitos" nas reformas. InfoMoney [blog], 26 nov. 2018. Disponível em: $<$ https://www.infomoney.com.br/blogs/economia-e-politica/pedromenezes/post/7777985/entenda-em-5-graficos-por-que-voce-precisa-perder-direitos-nasreformas>. Acesso em: 15 ago. 2019.

PIB do Brasil: histórico e evolução em gráficos. Gazeta do Povo [site], 29 abr. 2019. Disponível em: <https://infograficos.gazetadopovo.com.br/economia/pib-do-brasil/>. 29 abr 2019. Acesso em: 03 jun. 2019.

PINTO, Tales. O new deal. História do mundo [site]. Disponível em: <https://www.historiadomundo.com.br/idade-contemporanea/o-new-deal.htm>. Acesso em: 10 ago. 2019. 
PRESSE, France. Fannie Mae e Freddie Mac, a engrenagem essencial do crédito imobiliário nos EUA. G1 [site], Economia, 11 jul. 2008. Disponível em: $<$ http://g1.globo.com/Noticias/Economia_Negocios/0,,MUL643734-9356,00FANNIE+MAE+E+FREDDIE+MAC+A+ENGRENAGEM+ESSENCIAL+DO+CREDITO+ IMOBILIARIO+NOS+.html>. Acesso em: 12 ago. 2019.

SALTO, Felipe. Previdência Social: Diagnóstico e Reforma. Senado Federal [site], Instituição Fiscal Independente, Brasília, 13 mar. 2019. Disponível em: < https://www12.senado.leg.br/ifi/pdf/previdencia-social-diagnostico-ereforma/at_download/file>. Acesso em: 15 ago. 2019.

SCIARETTA, Toni; LANDIM, Raquel. Agência de risco S\&P rebaixa nota do Brasil, que perde selo de bom pagador. Folha de São Paulo, 10 set. 2015. Disponível em: $<$ https://www1.folha.uol.com.br/mercado/2015/09/1679688-agencia-de-risco-sp-corta-notado-brasil-para-grau-especulativo.shtml>. Acesso em: 05 jun. 2018.

VALENTE, Gabriela. Banco Central reduz juros para 6,5\%, menor taxa da história. O Globo, 21 mar. 2018. Disponível em: <https://oglobo.globo.com/economia/banco-central-reduzjuros-para-65-menor-taxa-da-historia-22512938>. Acesso em 07 jun. 2019. 